\title{
International Journal of Medical Research and Review
}

\section{Vaginal progesterone in prevention of preterm labour}

\author{
Sahoo P. ${ }^{\mathbf{1}}$, Kumar Patel N. ${ }^{2 *}$, Patel 0. ${ }^{3}$, Panigrahi A. ${ }^{4}$, Biswal S. ${ }^{\mathbf{5}}$, Rath B. ${ }^{6}$ \\ DOI: https://doi.org/10.17511/ijmrr.2020.i06.13
}

1 Prativa Sahoo, Junior Resident, Department of Pharmacology, Veer Surendra Sai Institute of Medical Sciences and Research, Burla, Odisha, India.

2* Nayan Kumar Patel, Assistant Professor, Department of Cardiology, Veer Surendra Sai Institute of Medical Sciences and Research, Burla, Odisha, India.

3 Ojaswini Patel, Associate Professor, Department of Obstetrics \& Genecology, Veer Surendra Sai Institute of Medical Sciences and Research, Burla, Odisha, India.

4 A.K Panigrahi, Associate Professor, 5 S.B. Biswal, Associate Professor, 6 Bhabagrahi Rath, HOD, 4,5,6 authors are afffiliated with Department of Pharmacology, Veer Surendra Sai Institute of Medical Sciences and Research, Burla, Odisha, India.

Introduction: Preterm birth, defined as childbirth occurring at less than 37 completed weeks or 259 days of gestation since the first day of a woman's last menstrual period, is one of the leading causes of neonatal morbidity and mortality. Across 184 countries, the rate of preterm birth ranges from $5 \%$ to $18 \%$ of babies born. Out of 27 million babies born every year (2018 data ) in India, 3.5 million babies born are premature. Recent literature review has shown that the use of Progesterone reduces risk of preterm birth. But there is little information available regarding the role of Progesterone in preventing preterm labour. Objectives: Primary objective of the study is to find out the incidence of preterm labour among pregnant women taking vaginal progesterone. Secondary objective is toassess the safety and efficacy of progesterone in feto-maternal outcome. Methods: This is a cross sectional study where100 prescriptions from IPD of Dept of O\&G, VIMSAR, Burla of women who had recently undergone labour with singleton gestation and with previous history of preterm labour were analysed. Incidence of preterm labour among those taking and not taking vaginal progesterone were compared. Results: There was decreased incidence of preterm labour as there is prolongation mean Gestational age by 9.383 weeks among pregnant women taking vaginal progesterone. Conclusions: In the present study, women taking vaginal progesterone had significantly lowered incidence preterm birth rate.

Keywords: Gestational age, Preterm birth, Singleton gestation, Vaginal progesterone

Corresponding Author

Nayan Kumar Patel, Assistant Professor, Department of Cardiology, Veer Surendra Sai Institute of Medical Sciences and Research, Burla, Odisha, India. Email: drnayanpt15@gmail.com
How to Cite this Article

To Browse

Sahoo P, Patel NK, Patel O, Panigrahi AK, Biswal SB, Rath B. Vaginal progesterone in prevention of preterm labour. Int J Med Res Rev. 2020;8(6):451456.

Available From

https://ijmrr.medresearch.in/index.php/ijmrr/article/ view/1225

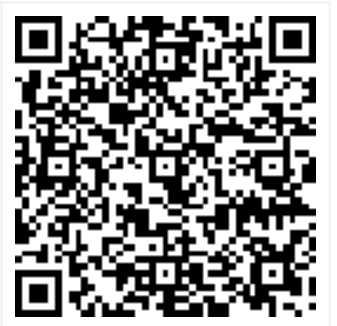

Manuscript Received 2020-11-13

Conflict of Interest No

Review Round 1
2020-11-23
Funding
Nil

Note 


\section{Introduction}

Preterm birth, defined as childbirth occurring at less than 37 completed weeks or 259 days of gestation since the first day of a woman's last menstrual period. Preterm labour is one of the leading causes of neonatal morbidity and mortality. $[1,2,3]$ Out of 27 million babies born every year (2018 data ) in India, 3.5 million babies born are premature, of whom many die as a consequences of prematurity . The burden of preterm birth and its associated neonatal mortality and morbidity is disproportionately borne by the world's poorest families.

Miscarriage is associated with considerable physical and psychological morbidity, particularly in developing countries (World health Organization,1992). Miscarriage is defined as pregnancy loss before 23 weeks' gestation, based on the first day of the last menstrual period. Recurrent miscarriage has been defined as 3 or more consecutive episodes of spontaneous pregnancy losses with the same biological father (World health Organization, 1992).[4]

Progesterone, a steroid hormone produced by corpus luteum is fundamental for pregnancy maintenance until the placenta (syncytio trophoblast) takes over its function at 7-9th week of gestation.It helps in development of a secretory endometrium by decreasing estrogen - driven endometrial proliferation. Itchanged Vaginal epithelium as condition of pregnancy.

It is important for the maintenance of pregnancy bysuppressing menstruation and uterine contractility. It also plays a role in the control of cervical ripening and has also effecton the pathway of parturition which may contribute to the prevention of preterm birth in women. Yet there is paucity of data available regarding use of vaginal progesterone in preterm labour.

\section{Materials and Methods}

This was a cross sectional study conducted in Dept. of $O \& G$, VIMSAR Burla with permission of VIREC, VIMSAR, Burla during the period June 19 to September 19. 100 women with a single ton pregnancy at 18-26 weeks GA were included in the study. Participants were all pregnant women, with a history of preterm labour, threatenedmiscarriage and a confirmed viable pregnancy.
All the cases were treated with $200 \mathrm{mg}$ micronized vaginal progesterone daily preferably at night till 36 weeks of GA and followed upto their delivery. women meeting the following inclusion criteria are eligible to participate in this study :(1) 18 years of age or older Patient having previous history of (2) Blighted Ovum (3) Preterm Labour In Short Cervix (4) Twin Pregnancy(5) Miscarriage or recurrent miscarriage (6) Abortion. (7) PROM - premature rupture of membrane or PPROM - preterm premature rupture of membrane.

We excluded from participation any woman with the additional exclusion criteria :Patient with history of (1) Hypertension (2) Diabetes Mellitus (3) Sickle cell disease (4) thalassemia (5) Drug or alcohol abuse (6) indication for planned delivery prior to 37 weeks( e.g. prior classical cesarean) (7) Fetal abnormalities (8) Uterine anomaly (9) known allergy to progesterone (10) cardiovascular diseases.

\section{Methodology}

Data collected from the medical records section of the hospital (who had history of previous preterm delivery and were taking vaginal progesterone 200mg OD).

Data was analysed for demographic status, Socio Economic Status, rate of term labour and preterm labour, comparison of Gestational Age of previous pregnancy with present pregnancy, duration of treatment, neonatal complication etc.

One scoring system named APGAR score is there to assess health of new born.

\section{Result}

Table 1:-Demographic characterstics

\begin{tabular}{|l|l|l|}
\hline \multicolumn{1}{|c|}{ SOCIO ECONOMIC STATUS } & \multicolumn{1}{|c|}{ PRETERM } & \multicolumn{1}{|c|}{ TERM } \\
\hline UPPER & 1 & 7 \\
\hline MIDDLE & 8 & 18 \\
\hline LOWER & 17 & 49 \\
\hline TOTAL & 26 & 74 \\
\hline
\end{tabular}

Table-1 shows association of gestational age at delivery with socio-economic status classified using B.G. Prasad's socio-economic status scale which was based on per capita monthly income. Maximum case of pre-term delivery seen in lower class which was 17 followed by middle class 8 . Maximum cases of term delivery seen in lower class which was 49 followed by middle class 18 . 
Fig1:- Distribution of age group according to gestational age at delivery

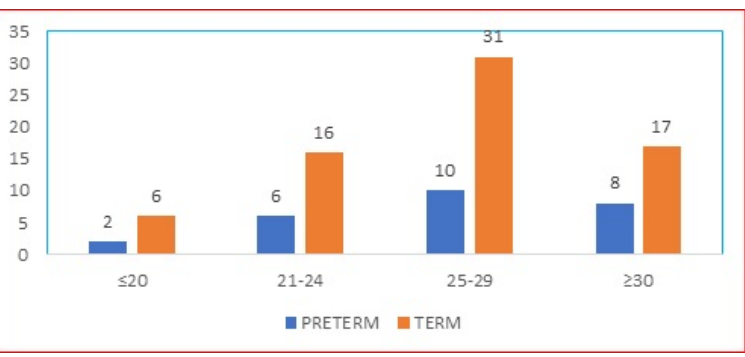

Figure-1 shows maximum number of cases term and preterm delivery was seen among 25-29 years group followed by 21-24 years.

Table 2:- Distribution of cases according to gestational age at delivery

\begin{tabular}{|l|l|}
\hline \multicolumn{1}{|c|}{ GA AT DELIVERY( WKS) } & \multicolumn{1}{c|}{ FREQUENCY $(\mathrm{N}=100)$} \\
\hline$\leq 33$ & 6 \\
\hline $34-36$ & 20 \\
\hline$\geq 37$ & 74 \\
\hline
\end{tabular}

Table-2 shows distribution of cases according to gestational age at delivery in week. Twenty six cases were preterm $\leq 37$ weeks, while 74 cases were term delivery i.e $\geq 37$ weeks.

Table 3:- Comparison of ga at delivbery with ga at previous delivery of preterm labor or midtrimester abortion

\begin{tabular}{|l|c|c|l|l|}
\hline \multicolumn{1}{|c|}{ GA } & MEAN & SD & SE OF MEAN & P VALU : \\
\cline { 1 - 3 } GA at delivery in present pregnancy & 37.92 & 1.769 & 0.228 & 0.001 \\
\cline { 1 - 3 } Mean GA At previous pregnancy & 28.53 & 5.472 & 0.706 & \\
\cline { 1 - 3 } Mean difference \pm SE in weeks & \multicolumn{3}{|l|}{$9.383 \pm 0.721$} & \\
\hline
\end{tabular}

Table-3 shows GA at delivery in present pregnancy had mean of $37.92 \pm 1.76$ weeks. Mean GA at delivery of previous pregnancy (Preterm Labour or mid- trimester abortion) was 28.53 \pm 5.47 weeks with a mean prolongation of Gestational age by $9.38 \pm 0.72$ which was found to be statistically significant( $P$ value-0.001).

Table 4: Association of ga at delivery with birth weight of newborns

\begin{tabular}{|l|l|l|l|}
\hline \multicolumn{1}{|c|}{ BW OF NEWBORN } & \multicolumn{1}{c|}{ PRETERM } & \multicolumn{1}{c|}{ TERM } & \multicolumn{1}{c|}{ TOTAL } \\
\hline$\geq 2.5 \mathrm{Kg}($ normal $)$ & 0 & $69(100 \%)$ & 69 \\
\hline $1.5-2.4 \mathrm{~kg}($ LBW $)$ & $19(79.2 \%)$ & $5(21.7 \%)$ & 24 \\
\hline$\leq 1.5 \mathrm{Kg}(\mathrm{VLBW})$ & $7(100 \%)$ & 0 & 7 \\
\hline
\end{tabular}

Table-4 shows distribution of birth weight of new born and its association with GA at delivery 19 LBW newborns were pre term and 5 LBW were term.
Table 5: Association of ga at delivery with apgar score at $1 \& \mathbf{5} \mathbf{~ m i n}$

\begin{tabular}{|l|l|l|l|}
\hline \multicolumn{1}{|c|}{ APGAR at $1 \mathrm{~min}$} & \multicolumn{1}{c|}{ PRETERM } & \multicolumn{1}{c|}{ TERM } & \multicolumn{1}{c|}{ TOTAL } \\
\hline$\leq 7$ & $18(64.3 \%)$ & $10(35.7 \%)$ & 28 \\
\hline$\geq 7$ & $8(11.1 \%)$ & $64(88.9 \%)$ & 72 \\
\hline
\end{tabular}

\begin{tabular}{|l|l|l|l|}
\hline \multicolumn{1}{|c|}{ APGAR at $5 \mathrm{~min}$} & \multicolumn{1}{c|}{ PRETERM } & \multicolumn{1}{c|}{ TERM } & \multicolumn{1}{c|}{ TOTAL } \\
\hline$\leq 7$ & $12(100 \%)$ & 0 & 12 \\
\hline$\geq 7$ & $14(15.9 \%)$ & $74(84.1 \%)$ & 88 \\
\hline
\end{tabular}

Table-5 shows APGAR at $1 \mathrm{~min}$ at $\leq 718$ new-borns are preterm while 8 new-borns are preterm with APGAR at 1 min at $\geq 7$.

APGAR at 5 min 12 new-borns are preterm belong to APGAR at $5 \mathrm{~min}$ at $\leq 7$. Hence less APGAR score at 1 and $5 \mathrm{~min}$ for preterm neonates as compared to terms.

Table 6:- Association of ga at delivery with duration of treatment

\begin{tabular}{|l|l|l|l|}
\hline DURATION OF TREATMENT(in weeks) & PRETERM & TERM & TOTAL \\
\hline S 8
\end{tabular}

\begin{tabular}{|l|l|l|l|}
\hline$\leq 8$ & 11 & 0 & 11 \\
\hline $9-13$ & 13 & 29 & 42 \\
\hline $14-18$ & 2 & 45 & 47 \\
\hline
\end{tabular}

Table- 6 shows least numbers of preterm labours seen with pregnant lady treated with maximum duration.

Fig 2:- Association of ga at delivery with neonatal complications of newborns

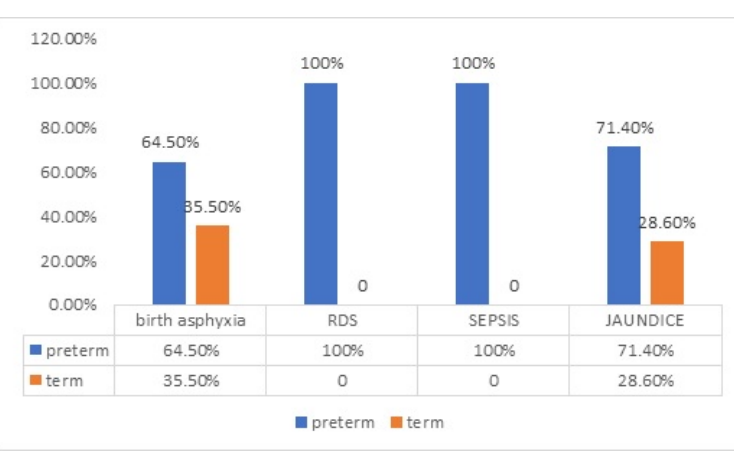

Fig 2 Shows maximum neonatal complications seen in preterm cases.

\section{Discussion}

Preterm birth is leading cause of perinatal morbidity and mortality and its prevention is an important health care priority.One of the causes of Preterm Labour is decline in progesterone action. So for this reason it has been proposed that progesterone deficiency can be corrected by administration of this hormone, thereby preventing preterm labour. 
The Mean maternal age in the study in 25-29 yrs age group which correspond to following studies like Meis et al (2003) 26 55.6 yrs, [5] Fonseca et al (2007) 29 yrs, [6] Hasan et al (2011) 26.5 \pm 5.8 years, [7] Bhadra et al (2014) 23.12 years, [8] Alavi et al (2016) years [9]. Maximum cases of preterm birth were seen among 25-29 years group.

Socioeconomic status was classified using B.G. Prasad's Socio-economic status scale which was based on per capita monthly income.The \% age of preterm labour is highest in lower Socio Economic Status.

After taking vaginal progesterone, the term labours are higher $(74 \%)$. Mean gestational age (GA) improved from 28.53 to 37.92 weeks. After taking vaginal progesterone as compared to other studies like Johnson et al (2003), Da Fonseca et al (2003), Garg etal (2014) [10] mean GA at delivery were 38.6 weeks, 35.2 weeks, 38 weeks respectively among progesterone group.

There is reduction in incidence of preterm labour as duration of treatment in weeks increases which corroborates with Meis etal,2003; [5] Fonseca et al, 2007; [6] Hassan et al, 2011 [7].

Progesterone supplementation is associated with a reduction in the rate of neonatal LBW, which corresponds with Meis et al, 2003- 27\% had birth weight $<2.5 \mathrm{~kg}$ in the progesterone group, Fonseca et al (2007)13.2\% had birth weight $<2.5 \mathrm{~kg}$ in the progesterone group as compared to $19.6 \%$ in placebo group, Hassan et al (2011) $6.4 \%$ had birth weight $<2.5 \mathrm{~kg}$ in the progesterone group as compared to $13.6 \%$ in placebo group. Garg et al (2014), Gupta et al (2015)[11] birth weight $<2.5$ $\mathrm{kg}$ in the progesterone group were $38.02 \%$ and $16.7 \%$ respectively.

Progesterone supplementation had better neonatal outcome in terms of better APGAR score and reduced morbidity and mortality, which corroborate with Peto (OR-0.74; 95\% CI-0.40-1.35, P = 0.32), Levine $L$ et al, 1964,[12] Meis et al (2003), [5] Elzibdeh et al, 2005, [13] Hassan et al (2011), [7] Wahabi et al., 2011, [14] Gupta etal (2015), [11] Alavi etal(2016) [9].

The overall meta-analysis conducted on the use of progestogens for the treatment of recurrent miscarriages (Haas and Ramsey et al, 2009)[15] showed no statistically significant difference in miscarriage rates between progestogens and placebo groups (Peto Or $0.98 ; 95 \%$ ci $0.78-1.24$ ).
No evidence for an effect favouring the use of progestogens in women with recurrent miscarriage was found when compared to placebo (Peto Or 1.11, $95 \%$ ci $0.79-1.56, \mathrm{P}=0.54$ ).

Only one study compared vaginally administered progestogens with placebo, a second one comparing it with no treatment. the incidence of recurrent miscarriage was similar in both groups (Peto Or $0.74 ; 95 \%$ ci0.40-1.35, $\mathrm{P}=0.32$ ).

The analysis concerning recurrent miscarriageconsidered 4 trials, of these 2 trials (Levine et al, 1964, El-Zibdeh et al, 2005) enrolled only women who had sufferedthree or more miscarriages, 2 others (Swyer and Daley et al, 1953 ;[16] Goldzieher et al, 1964) [17] provided separatepregnancy outcome data by number of previousconsecutive pregnancy losses.

The results showed areduction in miscarriage in favour of those in the progestogens group (Peto Or $0.38 ; 95 \% \mathrm{CI} 0.20$ to $0.70, \mathrm{P}=0.002$ ). This finding however should beapproached with caution as numbers are small.

A recent study [18] about the mechanisms of action of progestogens in vivo has shown that vaginal progesterone has local anti-inflammatory effects at the maternal-fetal interface. Specifically, when vaginal progesterone is administered to pregnant mice, it fosters an anti-inflammatory microenvironment at the maternal-fetal interface by increasing CD4+ Tregs and reducing CD8+CD25+Foxp3+ $T$ cells, macrophages, and interferon- $\gamma+$ neutrophils [18].

In addition, the administration of vaginal progesterone decreases the infiltration of active matrix metalloproteinase-9+ neutrophils and monocytes in the cervix, reduces the plasma concentration of interleukin-1 $\beta$, and reduces the frequency of endotoxininduced preterm birth [18].

In summary, progesterone has anti-inflammatory effects and also modulates other biological processes implicated in cervical ripening

\section{Limitation}

Maximum patient coming to Govt. Hospital are financially poor. For them it is difficult to use Progesteroneas its cost is high.So we have taken less number of cases. Patients are taken into consideration those having history of previous preterm labour or mid trimester abortion. 
So ultimately number of cases will be reduced.

Leakage of white sticky oily substance to the body lining or to the panty after insertion of progesterone tablet into vagina. So we preferably advised progesterone at bed time.

There will be withdrawal bleeding if we skip the medicine for 3 to 4 days by abrupt decline in progesterone which is the main determinant of the onset of menstruation.

\section{Contribution}

Dr. Prativa Sahoo: Helped in data collection and analysis \& preparation of manuscript.

Dr. Nayan Kumar Patel: Suggested to exclude patient with sickle cell disease, hyper tension, cardio-vascular disease, drug-alcohol abuse and diabetes mellitus, data analysis and preparation of manuscript.

Dr. Ojaswini Patel: Suggested to include patient having history of Blighted Ovum, Preterm Labour in Short Cervix, Twin Pregnancy, Miscarriage \& Abortion.

Dr. A.K Panigrahi, Dr. S.B. Biswal, Dr. Bhabagrahi Rath guided to conduct this study and preparation of manuscript.

Each author contributed to the writing of this manuscript. All authors critically reviewed and approved the final manuscript.

\section{Conclusion}

In the present study, treating the women having previous history of pre term delivery with vaginal progesterone had significantly lowered premature birth rate and its neonatal morbidity, better APGAR score. Although progesterone had no direct effect on neo natal parameter, reduction in morbidity was attributed to reduction in the rate of preterm birth.

Patient having short cervical length should be offered prophylactic administration of vaginal progesterone to prevent preterm birth.

The present paper aims to provide a comprehensive view of the literature on the effects of progestogen during pregnancy. It describes the effects of progesterone for preventing preterm labour, recurrent miscarriages and managing threatened miscarriage.

\section{Reference}

01. Lomazzi M, Borisch B, Laaser U. The millennium development goals- experiences, achievements and what's next. Glob Health Action. $2014 ; 7 ; 23695$.

[Crossref]

02. Steer P. The epidemiology of preterm labour. BJOG. 2005;112 Suppl 1;1-3.

[Crossref]

03. Wen SW, Smith G, Yang Q, Walker M. Epide miology of preterm birth and neonatal outcome. Semin Fetal Neonatal Med. 2004;9(6)429-35.

[Crossref]

04. World health Organization. international Statistical classification of Diseases and related health Problems. 10 ed, Geneva. 1992;1.

[Crossref]

05. Meis PJ, Klebanoff M, Thom E, Dombrowski MP, Sibai B, Moawad AH, et al. Prevention of recurrent preterm delivery by 17 alphahydroxyprogesterone caproate. N Engl J Med. 2003;348(24)2379-3285.

[Crossref]

06. Fonseca EB, Celik E, Parra M, Singh M, Nicolaides $\mathrm{KH}$. Progesterone and the risk of preterm birth among women with a short cervix. N Engl J Med. 2007;357(5)462-469.

[Crossref]

07. Hassan SS, Romero R, Vidyadhari D, Fusey S, Baxter JK, Khandelwal $M$, et al. Vaginal progesterone reduces the rate of preterm birth in women with a sonographic short cervix- a multicenter, randomized, double-blind, placebocontrolled trial. Ultrasound Obstet Gynecol. 2011;38(1)18-31.

DOI: $10.1002 / 14651858 . C D 003511 . p u b 2$ [Crossref]

08. Bhadra B, et al. Roll of progesterone in prevention of pre-term labour among women with short cervix. International medical journal. Aug 2014;1(8)451-454.

[Crossref]

09. Alavi $A$, et al. Effect of vaginal progesterone suppository $(200 \mathrm{mg})$ in preventing preterm labor after the inhibition of uterine contractionrandomised clinical trial. International journal of medical research and health sciences. 2016;5;10;21-26.

[Crossref] 
10. Garg R, et al. Progesterone and prevention of pre-term labour. Indian journal of clinical practice. Sep 2014;25(4)362-363.

[Crossref]

11. Gupta A, et al. Vaginal progesterone in asymptomatic women with short cervical length on ultrasound- is it beneficial. Journal of fetal medicine. Jun 2015;2(2)69-72.

[Crossref]

12. Levine L. Habitual abortion, a controlled clinical study of Progestational therapy. West J Surg Obstet Gynecol. 1964;72;30-36.

[Crossref]

13. El-Zibdeh MY. Dydrogesterone in the reduction of recurrent spontaneous abortion. J Steroid biochem Mol biol. 2005;97;431-434.

[Crossref]

14. Wahabi Ha, Abed Althagafi NF, Elawad M, Al Zeidan R. Progestogen for treating threatened miscarriage. Cochrane Database Syst rev. 2011; (3)cD005943.

DOI: $10.1002 / 14651858 . C D 005943 . p u b 3$ [Crossref]
15. Haas DM, Ramsey PS. Progestogen for preventing miscarriage. cochrane Database Syst rev. 2009; cD003511.

[Crossref]

16. SwyerGiM, Daley D. Progesterone implantation in habitual abortion. BMJ. 1953;1;1073-1086. [Crossref]

17. Goldzieher JW. Double-blind trial of a progestin in habitual abortion. JAMA. 1964;188;651-654. [Crossref]

18. Furcron $A E$, Romero $R$, Plazyo $O$, et al. Vaginal progesterone, but not 17alphahydroxyprogesterone caproate, has anti inflammatory effects at the murine maternalfetal interface. Am J Obstet Gynecol. $2015 ; 213 ; 846$. e1-19 [Crossref] 